\title{
ELECTROLUMINESCENT DISPLAY WITH PICTURE STORAGE
}

\author{
Z. PORADA $^{\mathrm{a}, *}$ and E. SCHABOWSKA-OSIOWSKA ${ }^{\mathrm{b}}$ \\ ${ }^{a}$ Institute of Electrical Engineering, Technical University, \\ Warszawska 24, 31-155 Kraków (Poland); \\ ${ }^{\mathrm{b}}$ Department of Electronics, Academy of Mining and Metallurgy, \\ Al. Mickiewicza 30, 30-059 Kraków (Poland)
}

(Received 20 April 1998; In final form 4 September 1998)

\begin{abstract}
Memory cells, composed of PC and EL thin film elements, have been utilized to designing of a display with picture storage. Such a picture storing electroluminescent display may prove competitive with used now picture storing methods in the digital form. A mathematical model suitable for analysing the properties of a PC-El system is proposed and the preparation of PC and EL thin film elements is described. For a single pixel the dependences of output signal on the time for various values of amplitude and frequency of supplying voltage are presented.
\end{abstract}

Keywords: Optoelectronics; thin films; display

\section{INTRODUCTION}

The increased utilization of various optoelectronic systems has generated interests in optoelectronic circuits with photoconducting (PC) and electroluminescent (EL) thin film devices. They are frequently applied as logical gates, amplifiers of weak light signals [1] and because of the optical feedback in such systems, they can work as memory cells $[2,3]$.

Memory cells, composed of PC and EL thin film elements, can be utilized, among others, to designing of a display with picture storage.

*Corresponding author. 
Electroluminescent displays of such type are rated as active, e.g., light emitting displays.

An electroluminescent display is generally in the shape of a matrix, in which the elements of a picture are formed in the points of intersection of horizontal (lines) and vertical (columns) strip electrodes. Using such configuration of electrodes it is possible to address $m \times n$ elements of the picture (pixels) by means of " $m$ " lines and " $n$ " columns. The excitation of the pixels may be realized by successive applying of voltages to the electrodes of lines and columns [4]. Such excitation of display's elements shows a number of disadvantages, which can be avoided using the excitation of particular pixels by a light beam. With an adequate structure of systems with single pixels utilizing PC and EL elements a display which will store the pictures can be obtained.

An individual pixel, i.e., separate "point" of projected picture, can be obtained by suitable connection of three photoconducting (PC) and two electroluminescent (EL) elements (Fig. 1). The whole display composed of optional number of pixels, is supplied with sinusoidal voltage so selected as the voltage on every of pixels to be sufficient to produce an emission from the electroluminescent element. Owing to the optical feedback between $\mathrm{EL}_{1}$ element and $\mathrm{PC}_{1}$ element, the $\mathrm{PC}_{1}-$ $\mathrm{EL}_{1}$ system composed of these elements can be a bistable system, i.e.,

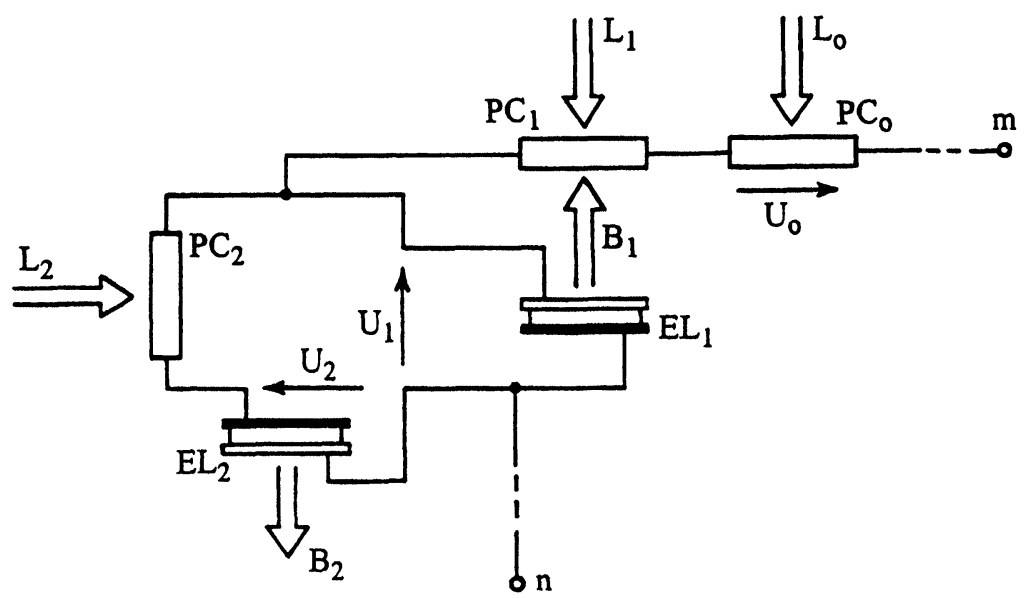

FIGURE 1 PC-EL system with individual pixel. 
can be in the "ON"-state or in the "OFF"-state and then the second EL element will emit a light signal corresponding only to an individual pixel when the $\mathrm{PC}_{1}-\mathrm{EL}_{1}$ system is in the "ON"-state.

The theoretical analysis shows that a $\mathrm{PC}_{1}-\mathrm{EL}_{1}$ system with optical feedback may be a bistable system on condition that the feedback coefficient $\beta$ will have a value higher than $\beta_{\text {LIM }}$. As demonstrated in carried out investigations, the limiting value $\beta_{\text {LIM }}$ depends on the amplitude of the voltage supplying the $\mathrm{PC}_{1}-\mathrm{EL}_{1}$ system as well as on its frequency $[5,6]$.

If a $\mathrm{PC}_{1}$ device is illuminated with an input signal $L_{1}$, then at the output of the bistable $\mathrm{PC}_{1}-\mathrm{EL}_{1}$ system a signal $B_{1}$ appears as the light emitted from the electroluminescent device $\mathrm{EL}_{1}$ which additionally illuminates the $\mathrm{PC}_{1}$ device. When the output signal $B_{1}$ does not fall to zero, in spite of "switching off" the input signal $L_{1}$, then the $\mathrm{PC}_{1}-\mathrm{EL}_{1}$ system is in the on-state, that is to say it remembers that previously it had been illuminated with the input signal $L_{1}$.

Assuming the $\mathrm{PC}_{1}-\mathrm{EL}_{1}$ system to be in the on-state, the application of the second input signal $L_{2}$, illuminating the $\mathrm{PC}_{2}$ device, causes the appearance of the output signal $B_{2}$ in the form of light emitted from the electroluminescent device $\mathrm{EL}_{2}$.

As the $\mathrm{PC}_{2}-\mathrm{EL}_{2}$ system is one without optical feedback, the removal of the input signal $L_{2}$ results every time in the decay of the output signal $B_{2}$ to a value not far from zero.

\section{THEORETICAL CONSIDERATION}

A mathematical model suitable for analysing the properties of a PCEL system is proposed using the circuit shown in Figure 1.

The instantaneous value of the current $i_{1}^{\mathrm{PC}}$ through a $\mathrm{PC}_{1}$ element is given [7] by the formula:

$$
i_{1}^{\mathrm{PC}}=u_{1}^{\mathrm{PC}}\left(G_{01}+G_{1}^{\mathrm{PC}}\right) /\left(1+\omega^{2} \tau_{1}^{2}\right),
$$

where $u_{1}^{\mathrm{PC}}$ is the instantaneous value of the voltage on the $\mathrm{PC}_{1}$ element, $G_{01}$ is the dark conductance of the $\mathrm{PC}_{1}$ element, $G_{1}^{\mathrm{PC}}$ is the instantaneous value of conductance of $\mathrm{PC}_{1}$ element illuminated with a light of illumination $L, \omega$ is angular frequency of the alternating 
sinusoidal voltage supplying the PC-EL system and $\tau_{1}$ is average relaxation time of $\mathrm{PC}_{1}$ element. The illumination $L$ is given by the expression:

$$
L=L_{1}+\beta B_{1}
$$

where $L_{1}$ is the instantaneous value of illumination of $\mathrm{PC}_{1}$ element by an external light source, $B_{1}$ is the instantaneous value of luminance of electroluminescent cell $\mathrm{EL}_{1}$ and $\beta$ is the optical feedback coefficient of $\mathrm{PC}_{1}$ element with $\mathrm{EL}_{1}$ element.

The instantaneous value of conductance $G_{1}^{\mathrm{PC}}$ may be calculated [8] by solving the equation:

$$
\frac{d}{d t} G_{1}^{\mathrm{PC}}=a_{1}\left(L_{1}+\beta B_{1}\right)-\frac{G_{1}^{\mathrm{PC}}}{\tau_{g 1}},
$$

where $a_{1}$ is a constant for the $\mathrm{PC}_{1}$ element, and $\tau_{g 1}$ is the photoconductivity growth time for this element.

The instantaneous value of luminance $B_{1}$ can be given [9] by the formula:

$$
B_{1}=B_{01} \exp \left(-\gamma_{1} t\right) \exp \left(-b_{1} / \sqrt{\left|u_{1}\right|}\right),
$$

where $B_{01}, \gamma_{1}$ and $b_{1}$ are constant values for $\mathrm{EL}_{1}$ element, and $u_{1}$ is the instantaneous value of the voltage across this element.

The instantaneous value of the current $i_{1}^{\mathrm{EL}}$ through an $\mathrm{EL}_{1}$ element is given by:

$$
i_{1}^{\mathrm{EL}}=C_{1}^{\mathrm{EL}} \frac{d}{d t} u_{1}+G_{1}^{\mathrm{EL}} u_{1}
$$

where $G_{1}^{\mathrm{EL}}$ and $C_{1}^{\mathrm{EL}}$ are the leakage conductance and the capacitance for $\mathrm{EL}_{1}$ element respectively.

The instantaneous value of the current $i_{0}^{\mathrm{PC}}$ through a $\mathrm{PC}_{0}$ element is given by the formula:

$$
i_{0}^{\mathrm{PC}}=u_{0}\left(G_{0}+G_{0}^{\mathrm{PC}}\right) /\left(1+\omega^{2} \tau_{0}^{2}\right)
$$

where $u_{0}$ is the instantaneous value of the voltage on the $\mathrm{PC}_{0}$ element, $G_{0}^{\mathrm{PC}}$ is the instantaneous value of conductance of $\mathrm{PC}_{0}$ element 
illuminated with a light of illumination $L_{0}, G_{0}$ is dark conductance of $\mathrm{PC}_{0}$ element, and $\tau_{0}$ is average relaxation time of this element.

Since $i_{1}^{\mathrm{PC}}=i_{0}^{\mathrm{PC}}$ and $u_{1}^{\mathrm{PC}}=u-u_{1}-u_{0}$, where $u$ is the instantaneous value of the voltage supplying the PC-EL system, the equation:

$$
\left(u-u_{1}-u_{0}\right) \frac{G_{0}+G_{1}^{\mathrm{PC}}}{1+\omega^{2} \tau_{1}^{2}}=u_{0} \frac{G_{0}+G_{0}^{\mathrm{PC}}}{1+\omega^{2} \tau_{0}^{2}}
$$

is obtained.

The instantaneous value of conductance $G_{0}^{\mathrm{PC}}$ may be calculated by solving the equation:

$$
\frac{d}{d t} G_{0}^{\mathrm{PC}}=a_{0} L_{0}-\frac{G_{0}^{\mathrm{PC}}}{\tau_{g 0}}
$$

where $a_{0}$ and $\tau_{g 0}$ are the constant and the photoconductivity growth time for $\mathrm{PC}_{0}$ element respectively.

The instantaneous value of the current $i_{2}^{\mathrm{PC}}$ through a $\mathrm{PC}_{2}$ element is given by the formula:

$$
i_{2}^{\mathrm{PC}}=u_{2}^{\mathrm{PC}}\left(G_{02}+G_{2}^{\mathrm{PC}}\right) /\left(1+\omega^{2} \tau_{2}^{2}\right)
$$

where $u_{2}^{\mathrm{PC}}$ is the instantaneous value of the voltage on the $\mathrm{PC}_{2}$ element, $G_{2}^{\mathrm{PC}}$ is the instantaneous value of conductance of $\mathrm{PC}_{2}$ element illuminated with a light of illumination $L_{2}, G_{02}$ is dark conductance of the $\mathrm{PC}_{2}$ element and $\tau_{2}$ is average relaxation time of this element.

The instantaneous value of conductance $G_{2}^{\mathrm{PC}}$ may be calculated by solving the equation:

$$
\frac{d}{d t} G_{2}^{\mathrm{PC}}=a_{2} L_{2}-\frac{G_{2}^{\mathrm{PC}}}{\tau_{g 2}}
$$

where $a_{2}$ and $\tau_{g 2}$ are the constant and the photoconductivity growth time for $\mathrm{PC}_{2}$ element respectively.

The instantaneous value of luminance $B_{2}$ of electroluminescent element $\mathrm{EL}_{2}$, can be given by the formula:

$$
B_{2}=B_{02} \exp \left(-\gamma_{2} t\right) \exp \left(-b_{2} / \sqrt{\left|u_{2}\right|}\right)
$$


where $B_{02}, \gamma_{2}, b_{2}$ are constant values for $\mathrm{EL}_{2}$ element, and $u_{2}$ is the instantaneous value of the voltage across this element.

The instantaneous value of the current $i_{2}^{\mathrm{EL}}$ through an $\mathrm{EL}_{2}$ element is given by:

$$
i_{2}^{\mathrm{EL}}=C_{2}^{\mathrm{EL}} \frac{d}{d t} u_{2}+G_{2}^{E L} u_{2}
$$

where $G_{2}^{\mathrm{EL}}$ and $C_{2}^{\mathrm{EL}}$ are leakage conductance and the capacitance for $\mathrm{EL}_{2}$ element, respectively.

Since: $i_{2}^{\mathrm{PC}}=i_{2}^{\mathrm{EL}}, i_{1}^{\mathrm{PC}}=i_{1}^{\mathrm{EL}}+i_{2}^{\mathrm{PC}}$ and $u_{2}^{\mathrm{PC}}=u_{1}-u_{2}$, the equations

$$
C_{2}^{\mathrm{EL}} \frac{d}{d t} u_{2}+G_{2}^{\mathrm{EL}} u_{2}+u_{2} \frac{G_{02}+G_{2}^{\mathrm{PC}}}{1+\omega^{2} \tau_{2}^{2}}=u_{1} \frac{G_{02}+G_{2}^{\mathrm{PC}}}{1+\omega^{2} \tau_{2}^{2}}
$$

and

$$
\left(u-u_{1}-u_{0}\right) \frac{G_{01}+G_{1}^{\mathrm{PC}}}{1+\omega^{2} \tau_{1}^{2}}=C_{1}^{\mathrm{EL}} \frac{d}{d t} u_{1}+G_{1}^{\mathrm{EL}} u_{1}+C_{2}^{\mathrm{EL}} \frac{d}{d t} u_{2}+G_{2}^{\mathrm{EL}} u_{2}
$$

are obtained.

Solving the set of Eqs. (3), (4), (7), (8), (10), (11), (13) and (14), the time dependence of the luminances $B_{1}$ and $B_{2}$ of the elements $\mathrm{EL}_{1}$ and $\mathrm{EL}_{2}$ were computed. The computations were carried out for the case, when the $\mathrm{PC}_{1}-\mathrm{EL}_{1}$ system was in the state "switched on", and when this system was in the state "switched off".

\section{EXPERIMENTS AND RESULTS}

The PC devices can be prepared as gate-type systems on a glass substrate [3]. The photoconductive layer was a $\mathrm{CdS}$ film doped with copper and chlorine and evaporated under vacuum at a pressure $0.007 \mathrm{~Pa}$. Special purity undoped cadmium sulphide was used. It was evaporated from an alundum crucible heated by a tungsten wire resistor. The temperature of the source was in the range of $900^{\circ} \mathrm{C}$ to $950^{\circ} \mathrm{C}$. The distance of the substrate from the source was $12 \mathrm{~cm}$. During evaporation the temperature of the substrate was held 
constant at $150^{\circ} \mathrm{C}$. CdS films were simultaneously doped with $\mathrm{Cu}$ and $\mathrm{Cl}$, and recrystallized by heating the films whilst embedded in a $\mathrm{CdS}$ powder that had previously been doped with $\mathrm{Cu}$ and $\mathrm{Cl}$. The recrystallization was carried out at $550^{\circ} \mathrm{C}$ in air for $30 \mathrm{~min}$. The thickness of $\mathrm{CdS}(\mathrm{Cu}, \mathrm{Cl})$ films was in the range of 6 to $14 \mu \mathrm{m}$. A metallic indium layer, deposited by vacuum evaporation, formed the upper electrode.

The electroluminescent device was a thin film capacitor produced by the vacuum evaporation of copper-, chlorine- and manganese-doped $\mathrm{ZnS}$. The evaporation was carried out under the presssure of $0.01 \mathrm{~Pa}$ from an alundum crucible heated to about $1100^{\circ} \mathrm{C}$ onto the substrate, which was placed $8 \mathrm{~cm}$ apart from the source and heated to $200^{\circ} \mathrm{C}$. The obtained $\mathrm{ZnS}(\mathrm{Cu}, \mathrm{Cl}, \mathrm{Mn})$ films were recrystallized by heating in a vacuum for $30 \mathrm{~min}$ at $300^{\circ} \mathrm{C}$. The thickness of $\mathrm{ZnS}(\mathrm{Cu}, \mathrm{Cl}, \mathrm{Mn})$ films was in the range of 0.6 to $1.3 \mu \mathrm{m}$.

The lower transparent conducting electrode was tin-doped $\operatorname{In}_{2} \mathrm{O}_{3}$, obtained by the reactive cathode sputtering of $90 \% \mathrm{In}-10 \% \mathrm{Sn}$ alloy on a glass substrate [3], while the upper electrode was a vacuumevaporated thin aluminium film.

A PC-EL system shown in Figure 1 was supplied with sinusoidal voltage. The input signal was in the shape of rectangular light pulses illuminating the photoconducting elements and the output signal was the luminance of the electroluminescent element $\mathrm{EL}_{2}$.

The theoretical analysis has shown that a $\mathrm{PC}_{1}-\mathrm{EL}_{1}$ system with optical feedback may be a bistable system [5] on condition that the feedback coefficient $\beta$ will have a value higher than $\beta_{\text {LIM }}$. As demonstrated in carried out investigations [6] the limiting value $\beta_{\text {LIM }}$ depends on the amplitude and frequency of the voltage supplying the PC-EL system (Fig. 2).

In Figure 3 the dependences of luminance $B_{1}$ amplitude on various values of input signal $L_{1}$ by fixed duration of this signal $(\Delta t=0.5 \mathrm{~ms})$ and fixed parameters of supplying voltage $\left(U_{0}=280,420\right.$ and $560 \mathrm{~V}$, $f=500 \mathrm{~Hz})$ are presented. For the input signal $\left(L_{1}<L_{\text {LIM }}\right)$ the output signal $B_{1}$ vanishes with time. For $L_{1}=L_{\text {LIM }}$ the second pulse $B_{1}$ has the same amplitude as the first pulse, it is then a boundary case for $\mathrm{PC}_{1}-\mathrm{EL}_{1}$ system. For $L_{1}>L_{\mathrm{LIM}}-$ the second pulse of signal $B_{1}$ is higher than the first pulse, thus even at switched off $L_{1}$ signal the system $\mathrm{PC}_{1}, \mathrm{EL}_{1}$ will be in the $\mathrm{ON}$ state. 


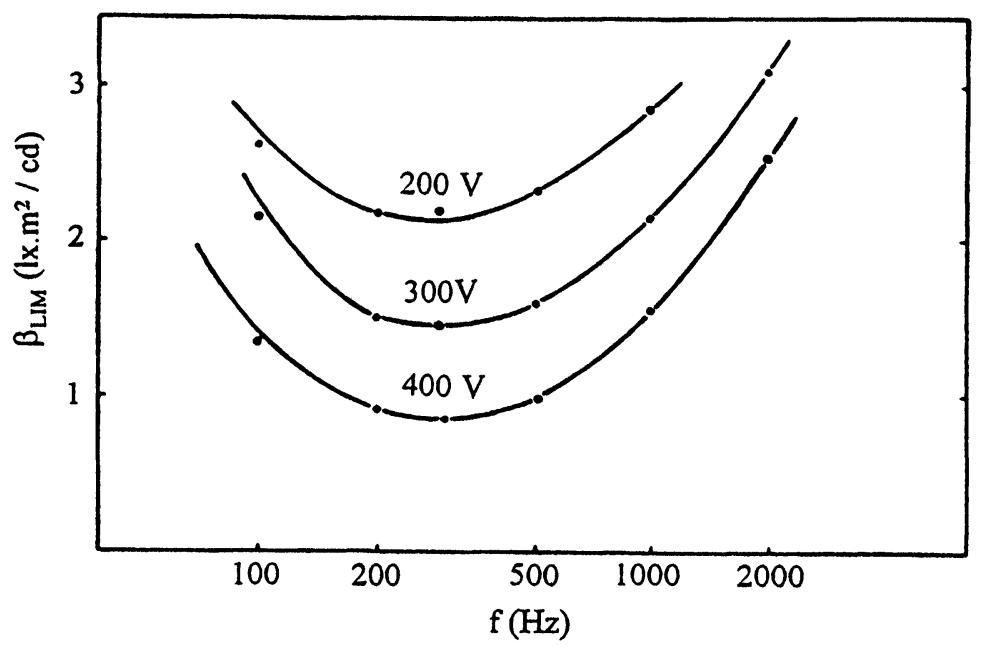

FIGURE 2 Dependences of the coefficient $\beta_{\text {LIM }}$ on the frequency for three values of supplying voltage.

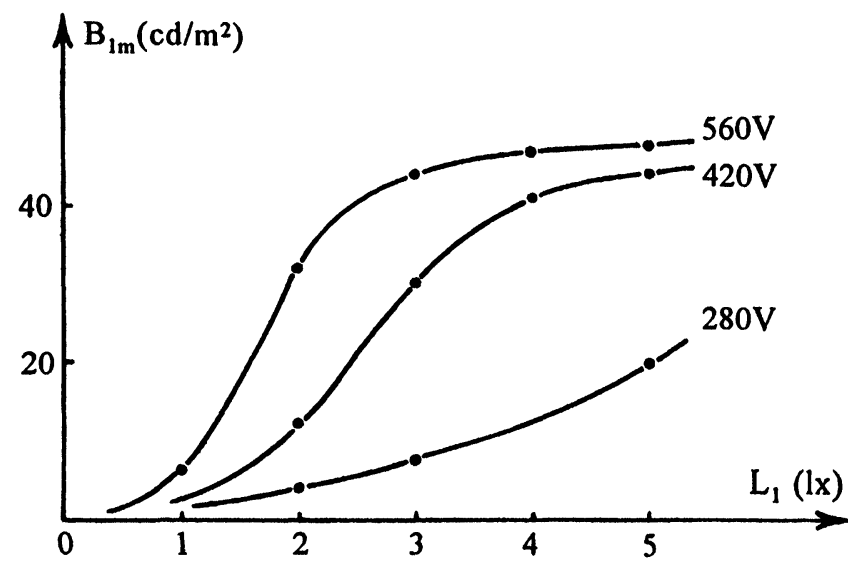

FIGURE 3 Dependences of luminance $B_{1}$ amplitude on various values of input signal $L_{1}$.

Figure 4 shows the dependence of luminance $B_{2}$ on the time for applied voltage of amplitude $420 \mathrm{~V}$ at frequencies 200, 500 and $1000 \mathrm{~Hz}$, at illumination of the PC elements with light pulses of $L_{1}=20 \mathrm{~lx}$ and duration $t_{0}=0.5 \mathrm{~ms}$, (both $L_{2}=20 \mathrm{~lx}$ and $L_{0}=201 \mathrm{x}$ ). 

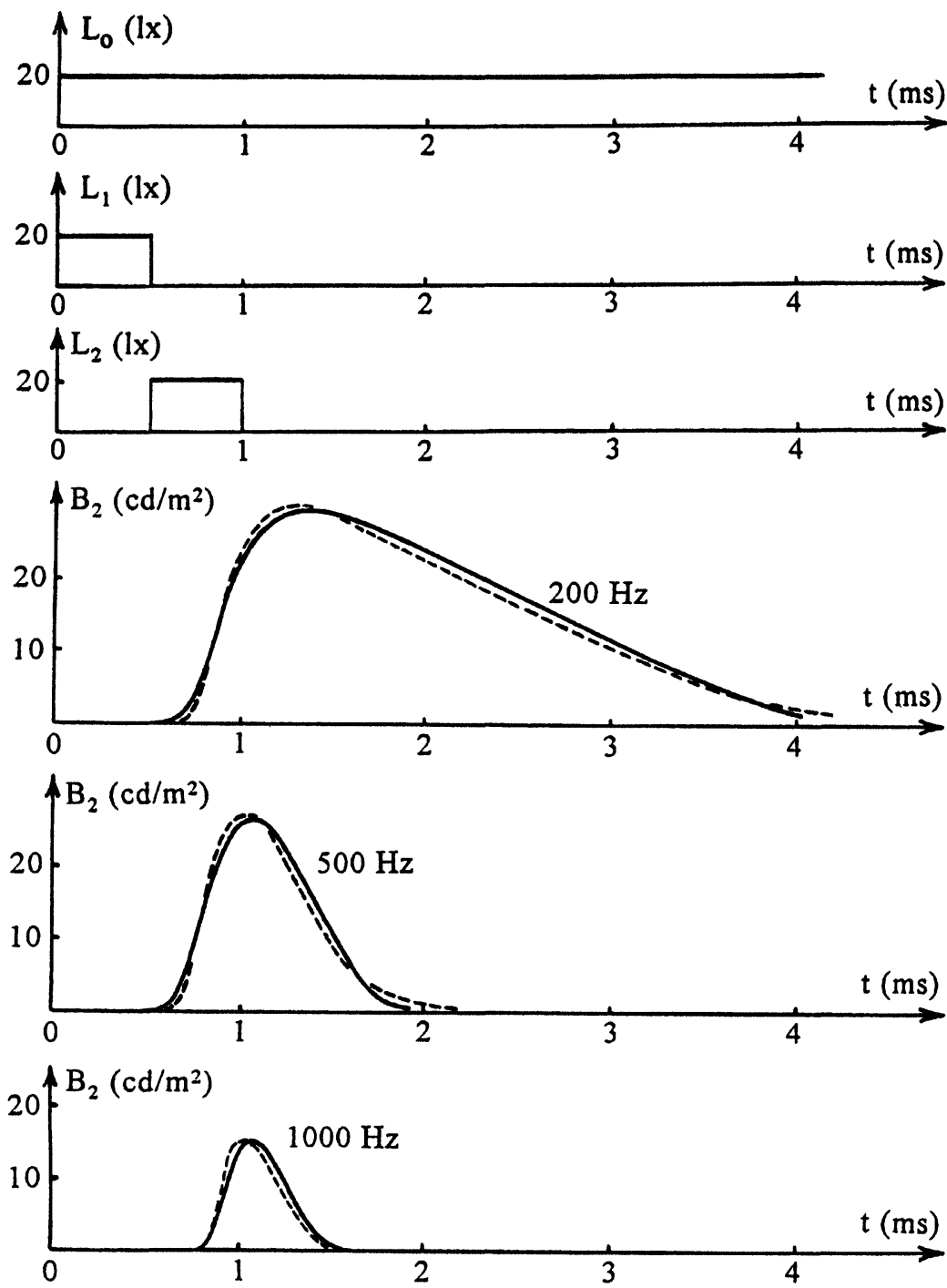

FIGURE 4 Dependence of luminance $B_{2}$ on the time for applied voltage of amplitude $420 \mathrm{~V}$ at frequencies 200,500 and $1000 \mathrm{~Hz}$.

In Figure 5 the dependence of $B_{2}$ on the time for frequency $500 \mathrm{~Hz}$ and three values of supplying voltage amplitude (280, 420 and $560 \mathrm{~V})$ are presented. 


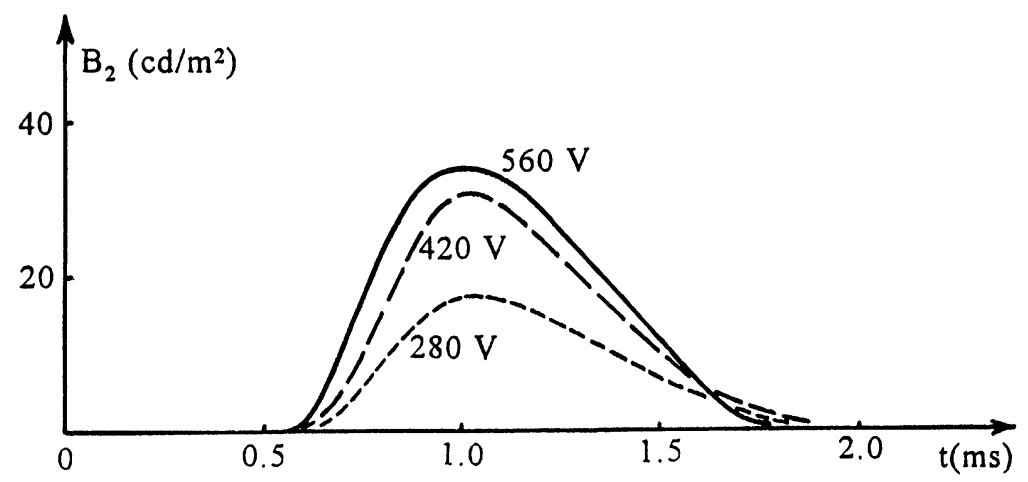

FIGURE 5 Dependence of $B_{2}$ on the time for frequency $500 \mathrm{~Hz}$ and three values of supplying voltage amplitude $(280,420$ and $560 \mathrm{~V})$.

In many cases can arise the necessity of "switching out" of a memory cell, being in the "ON" state. It is possible owing to the utilization of $\mathrm{PC}_{0}$ photoelement, because the switching off of the light signal $L_{0}$ for a sufficient length of time will result in considerable decrease of the voltage on the $\mathrm{EL}_{1}$ element and the luminance $B_{1}$ of this element will fall in practice to zero. Thus, wanting signal $L_{1}$, the system $\mathrm{PC}_{1}-\mathrm{EL}_{1}$ will be in the "OFF"-state.

Erasing the whole pictures stored by the display can be realized for the best by switching off for an adequately long time all supplying voltage.

\section{CONCLUSIONS}

It results from the investigations carried out by the authors, that thin film photoconducting and electroluminescent elements can be applied in constructing of electroluminescent display excited with a light beam, and in particular of pictures storing displays. In the constructing of such displays an important part is played by single $\mathrm{PC}_{1}-\mathrm{EL}_{1}$ systems, which can be transposed into the "ON"-state on condition that they are bistable systems.

The illumination with a light beam $L_{1}$ of adequate elements $\mathrm{PC}_{1}$ of whole display will cause that adequate $\mathrm{PC}_{1}-\mathrm{EL}_{1}$ systems will be in the 
"ON"-state. For the display shows us a stored picture, composed of many pixels, one should illuminate to this end all the elements $\mathrm{PC}_{2}$ of whole display with the light of intensity $L_{2}$. Then only these electroluminescent cells, which are connected with adequate $\mathrm{PC}_{1}-$ $\mathrm{EL}_{1}$ systems, being in the "ON"-state, will emit the light, showing the whole stored picture. The showing time of stored picture will be depending on the duration of signal $L_{2}$, playing the role of an information read-out signal.

The picture storing electroluminescent display presented in this work may prove - in many cases - competitive with used now picture storing methods in the digital form and their locating in the computer store, since so stored pictures occupy substantial part of this store.

\section{References}

[1] Szepesi, Z. (1972). Thin Solid Films, 13, 397.

[2] Henisch, H. K., Electroluminescence, Pergamon Press, Oxford (1962).

[3] Porada, Z. and Schabowska-Osiowska, E. (1991). Materials Science and Engineering, B9, 383.

[4] Żmija, J., Zieliński, J., Parka, J. and Nowinowski-Kruszelnicki, J., Displeje ciektokrystaliczne, PWN, Warszawa, 1993 (in Polish).

[5] Porada, Z. (1983). Thin Solid Films, 109, 213.

[6] Porada, Z. and Schabowska-Osiowska, E. (1989). Active and Passive Elec. Comp., 13,151

[7] Porada, Z., Optoelectronic systems with thin film photoconducting and electroluminescent elements. Technical University of Cracow, Cracow 1994, Monography No. 182 (in Polish).

[8] Porada, Z. and Schabowska-Osiowska, E. (1997). Active and Passive Elec. Comp., $20,53$.

[9] Alfrey, G. F. and Taylor, J. B. (1955). Brit. J. Appl. Physics, 4, 44S (Supplement). 

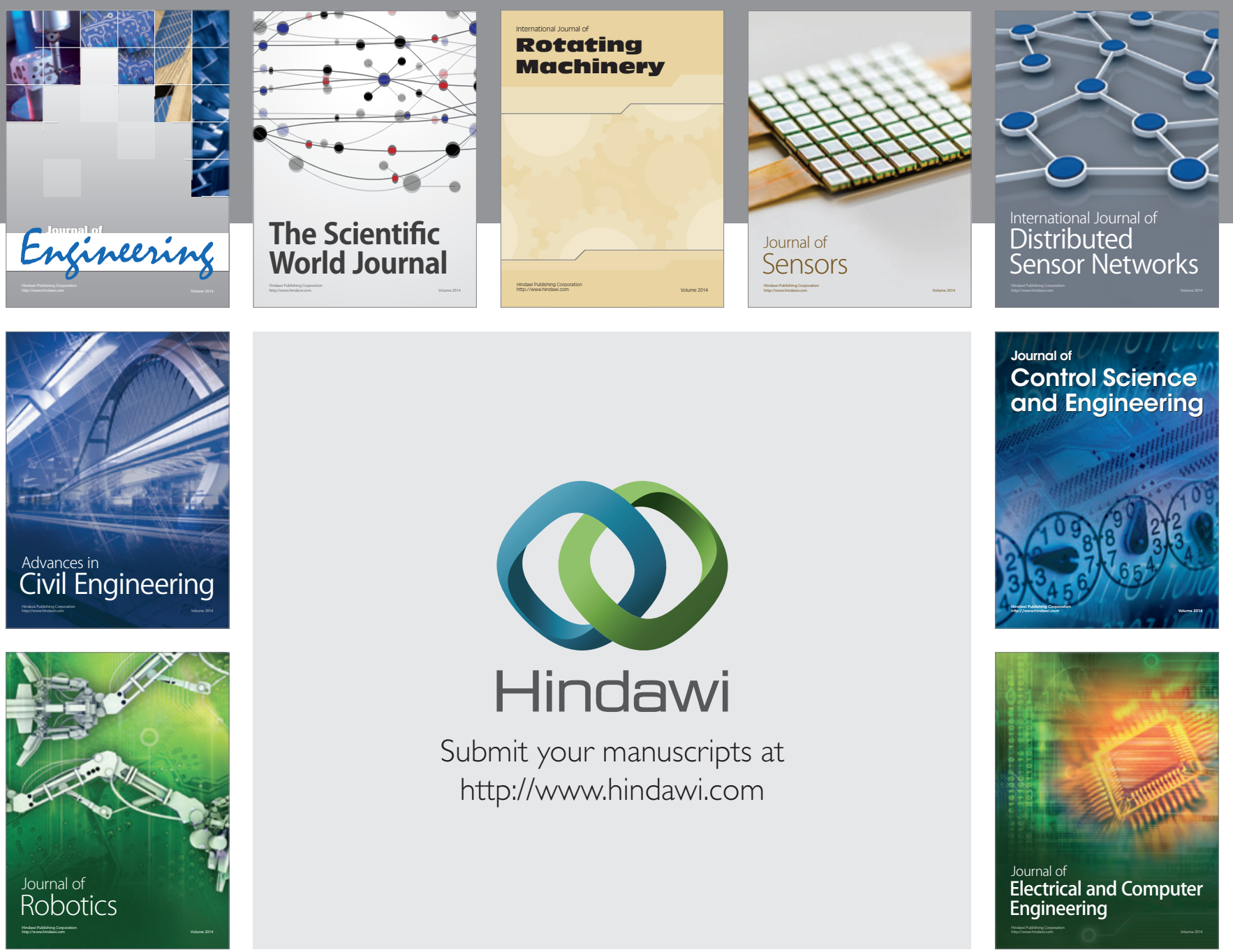

Submit your manuscripts at

http://www.hindawi.com
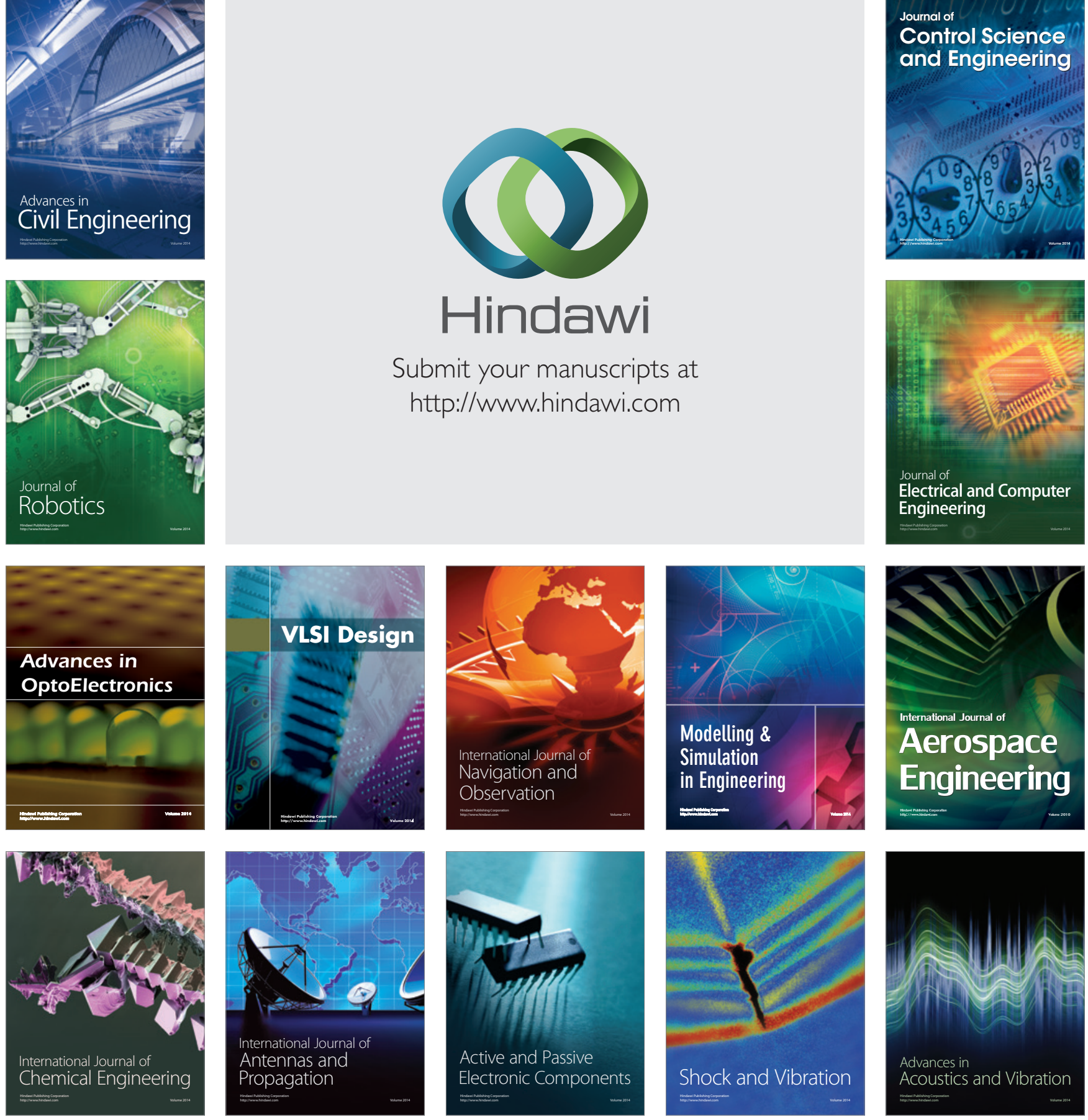